\title{
O USO DE RECURSOS DIDÁTICOS COMO ESTRATÉGIANO ENSINO DE CIÊNCIAS E BIOLOGIA
}

LOPES, Mario Marcos. Mestre em Desenvolvimento Regional e Meio Ambiente pelo Centro Universitário de Araraquara - UNIARA, Especialista em Didática e Tendências Pedagógicas pela Faculdade São Luís de Jaboticabal, Professor tutor do Curso de Aperfeiçoamento em Educação Ambiental pela Universidade de São

Paulo - Unifesp. Docente da Rede Estadual de Ensino de São Paulo. E-mail: mmarlopes@ig.com.br.

PLATZER, Maria Betânea. Doutora em Educação pela Universidade Estadual de Campinas - Unicamp. Docente nos cursos de Pedagogia e Ciências Biológicas do Centro Universitário de Araraquara - UNIARA. Integrante do Grupo de Estudos e Pesquisas em Formação Docente e Práticas Pedagógicas (CNPq/UNIARA). E-mail: beplatzer@yahoo.com.br.

\section{Resumo}

O ensino de Ciências e Biologia é recente na escola, e tem sido praticado de acordo com diferentes propostas educacionais, que se instalaram ao longo das décadas. ALDB (Lei n. ${ }^{\circ}$ 9.394, de 20 de dezembro de 1996) propõe um projeto pedagógico que vá além de lousa, giz e palestra do professor, a fim de preparar melhor o educando para os desafios do mercado de trabalho. Nesse sentido, este artigo pretende contribuir para a discussão referente à prática pedagógica e aos recursos didáticos que possam auxiliar no processo de ensino e aprendizagem, especialmente nas disciplinas de Ciências e de Biologia. A partir de uma abordagem qualitativa, esta pesquisa pretende contribuir para construção de novos conhecimentos que possam ser gerados a partir de um olhar cuidadoso e crítico das fontes documentais. Por fim, o grande desafio do educador é tornar o ensino de Ciências e Biologia prazeroso e instigante, sendo capaz de desenvolver no aluno o saber científico e o gosto por essas disciplinas.

Palavras-Chave: Didática; Ciências; Processo de ensino e aprendizagem; Recursos didáticos.

The use of Didactic Resources as a STRategy in Sciences and Biology teaching

\begin{abstract}
The teaching of Science and Biology at school is recent, and has been practiced according to the different educational proposals, that have been developed along the last decades. The LDB (Lei ${ }^{\circ}$ 9.394, December, $20,1996)$ proposes a pedagogical project that goes beyond the blackboard, chalk and teacher's talk in order to better prepare the students for the challenges of the labor market. Thus, this paper aims at contributing to the discussion on the teaching practice and teaching resources that can help the teaching and learning process, especially in the disciplines of Science and Biology. Based on a qualitative approach, this research aims at contributing to the construction of new knowledge that can be generated from a careful and criticallook at the documentary sources. Finally, the great challenge of the educator is to make the teaching of Scienceand Biology pleasurable and exciting, being able to develop in students the scientific knowledge and the taste for these school subjects.
\end{abstract}

KEYwORDs: Didactics; Science; Teaching and learning; Teaching resources. 


\section{INTRODUÇÃo}

As disciplinas de Ciências e Biologia passaram, ao longo da história, por diversas modificações e reformulações, influenciadas por variadas tendências educacionais e pelo contexto social vivenciado nas diferentes décadas. Nos dias atuais, temos percebido uma crescente busca por novos métodos, para que o ensino dessas disciplinas estimule a curiosidade dos alunos e os tornem capazes de compreender, explicar e intervir de forma consciente na natureza e na sociedade (CECCON, 2008).

Nesse contexto, o ensino de Ciências e Biologia deve proporcionar ao aluno a oportunidade de visualização de conceitos ou processos que estão sendo construídos por ele na escola. Sabe-se que o papel da educação é conduzir o crescimento intelectual, moral e ético através de ensinamentos, exemplos e experiências, fazendo com que cada indivíduo se conscientize e se responsabilize pelo destino da sua própria vida.

Entretanto, esse processo de aprendizagem pode ser complementado com a utilização de recursos didáticos audiovisuais, ferramentas computacionais, práticas no laboratório e na sala de aula e atividades externas; até o próprio livro didático, quando bem utilizado, pode ser uma ferramenta importante.

Diante do exposto, este artigo pretende contribuir para a discussão referente à prática pedagógica e aos recursos didáticos que podem auxiliar no processo de ensino e aprendizagem de Ciências e de Biologia.

Para tanto, optou-se pela pesquisa documental, bem como a pesquisa bibliográfica, ferramentas metodológicas utilizadas para alicerçar e sedimentar as discussões apresentadas, possibilitando ampliar a compreensão do tema proposto para estudo. A pesquisa assume ainda uma abordagem qualitativa, enfatizando não a descrição de informações recolhidas, mas a importância de novos conhecimentos que podem ser gerados a partir de um olhar cuidadoso e crítico das fontes documentais.

Por fim, os resultados apontam para um grande desafio, tornar o ensino de Ciências e Biologia prazerosos e instigantes, sendo capaz de desenvolver no aluno o saber científico. Nesse sentido, os diversos documentos têm lançado um sólido alicerce mediante o qual se podem buscar a organização e a reorganização da educação.

\section{Procedimentos medotológicos}

Por meio de uma revisão bibliográfica, buscaramse na literatura os estudos relacionados aos recursos didáticos e metodológicos, apontados pelos diversos pesquisadores, analisando as orientações e habilidades necessárias a esses dois campos de conhecimento (Ciências e Biologia). De acordo com Pádua (2000, p.65), a finalidade da pesquisa bibliográfica é "colocar o pesquisador em contato com o que já se produziu e registrou a respeito de seu tema de pesquisa".

Para que os objetivos propostos pudessem ser atingidos, o trabalho recorreu também à pesquisa documental, que se caracteriza pela consulta de leis, resoluções, portarias, decretos, enfim, todos os demais documentos que, de alguma forma, possam vir a auxiliar na busca de respostas ao problema de pesquisa. Pádua (2000, p.65) colabora ao afirmar que documento é "toda base de conhecimento fixado materialmente e suscetível de ser utilizado para consulta, estudo ou prova".

\section{Resultados E discussões}

\section{A evolução do ensino de Ciências e Biologia}

Para acompanhar as diversas mudanças das tendências educacionais, as disciplinas de Ciências e Biologia passaram por reformulações, de acordo com os acontecimentos das diferentes décadas. Apresentamos a trajetória dessas mudanças e o desafio dos docentes na busca por estratégias que provoquem nos educandos a curiosidade, tornando-os capazes de interpretar e intervir, de forma consciente, na natureza.

\section{O ensino de Ciências}

O ensino de Ciências é recente na escola de ensino fundamental, e tem sido praticado de acordo com diferentes propostas educacionais que se instalaram ao longo das décadas. Muitas das propostas, utilizadas ainda hoje, são baseadas na simples transmissão de 
conteúdo, tendo como recurso exclusivo o livro didático e a lousa; entretanto, outras já introduziram avanços produzidos nas últimas décadas, especialmente no ensino de Ciências (BRASIL, 1998).

Até o estabelecimento da Lei de Diretrizes e Bases da Educação - LDB, em 1961, as aulas de Ciências Naturais eram ministradas apenas nas duas últimas séries do antigo curso ginasial. A LDB n. ${ }^{\circ} 4.024$ estendeu a obrigatoriedade do ensino da disciplina a todas as séries ginasiais e, a partir de 1971, com a Lei n. ${ }^{\circ}$ 5.692, o ensino de Ciências passou a ter caráter obrigatório nas oito séries do primeiro grau (BRASIL, 1998). ALei n. ${ }^{\circ} 10.172$, de 9 de janeiro de 2001, que estabeleceu a implantação progressiva do Ensino Fundamental de nove anos, manteve a obrigatoriedade da referida disciplina, constante da Base Nacional Comum da Matriz Curricular.

O cenário escolar brasileiro por muito tempo foi dominado pelo ensino tradicionalista, ainda que esforços de renovação estivessem surgindo. Aos professores cabia apenas a transmissão de conhecimentos acumulados ao longo do tempo pela humanidade, por meio de aulas expositivas; aos alunos, por sua vez, cabia a reprodução e repetição das informações.

Nessa época, a qualidade do ensino era definida pela quantidade de informações e conteúdos trabalhados. O principal recurso de estudo e avaliação era o questionário, ao qual os alunos deveriam responder detendo-se nas ideias apresentadas em aula ou no livro didático escolhido pelo professor.

Diante do exposto, surgiu a necessidade de renovação das propostas do ensino de Ciências, para que o currículo respondesse ao avanço do conhecimento científico e às demandas pedagógicas geradas por influência do movimento Escola Nova.

Essa nova tendência, segundo Azevedo et al. (2010), deslocou o eixo da questão pedagógica dos aspectos puramente lógicos para aspectos psicológicos, valorizando a participação ativa do aluno no processo de ensino e aprendizagem. As aulas práticas passaram a representar importante elemento para a compreensão ativa de conceitos, mesmo que sua implementação prática tenha sido difícil, em escala nacional.

A nova proposta para o ensino de Ciências passou a dar condições para o aluno vivenciar o que se chamava método científico, ou seja, a partir de suas observações, levantar hipóteses, testá-las, refutá-las e abandoná-las quando fosse o caso, trabalhando de forma a redescobrir conhecimentos.

Apesar de algumas mudanças não atingirem a maioria das escolas e terem criado a ideia no corpo docente de que somente com laboratórios é possível alguma modificação no ensino de Ciências, muitos materiais didáticos, produzidos segundo essa nova proposta de aprendizagem, constituíram um avanço relativo para a melhoria do ensino de Ciências Naturais, introduzindo novos conteúdos.

Transcorridos quase 30 anos, o ensino de Ciências ainda é trabalhado, em muitas salas de aula, não levando em conta sequer o progresso relativo que essa proposta representou. Durante a década de 80, no entanto, pesquisas (BRASIL, 1998) sobre o ensino de Ciências revelaram o que muitos professores já tinham percebido: que a experimentação, sem uma atitude investigativa maior, não garante a aprendizagem dos conhecimentos científicos.

No âmbito geral, as discussões sobre as novas tendências e correntes pedagógicas foram importantes e influenciaram o ensino de Ciências, enfatizando conteúdos socialmente relevantes, questionando tanto a abordagem quanto a organização dos conteúdos, identificando a necessidade de um ensino que integrasse os diferentes conteúdos, com um caráter também interdisciplinar, o que tem representado importante desafio para a didática da área.

A história da Ciência mostra que as teorias do passado podem auxiliar a compreensão das concepções dos estudantes do presente, além de constituir conteúdo relevante do aprendizado.

As diferentes propostas reconhecem, hoje, que os mais variados valores humanos não são alheios ao aprendizado científico, e a Ciência deve ser apreendida em suas relações com a Tecnologia e com as demais questões sociais e ambientais. Essas novas propostas inovadoras têm trazido reformulação de conteúdos e 
métodos, mas é preciso reconhecer que, na maior parte das salas de aula, persistem velhas práticas. Mudar tal estado de inércia não é algo que se possa fazer unicamente a partir de novas teorias, ainda que exija, sim, uma nova compreensão do sentido mesmo da educação, do processo no qual se aprende. O presente estudo pretende contribuir para essa nova compreensão (SÃO PAULO, 2008a).

\section{O ensino de Biologia}

Os Parâmetros Curriculares Nacionais para o Ensino Médio (BRASIL, 2000), entendidos como referenciais para a renovação e reelaboração da proposta curricular, afirmam que é objeto do estudo da Biologia o fenômeno vida em toda sua diversidade de manifestações. Esse fenômeno se caracteriza por um conjunto de processos organizados e integrados, no nível de uma célula, de um indivíduo, ou ainda de organismos no seu meio. As diferentes formas de vida estão sujeitas a transformações, que ocorrem no tempo e no espaço, sendo, ao mesmo tempo, propiciadoras de transformações no ambiente.

Ao longo da história da humanidade, diversas foram as explicações para o surgimento e a diversidade da vida, de modo que os modelos científicos conviveram e convivem com outros sistemas explicativos. $\mathrm{O}$ aprendizado da Biologia deve permitir a compreensão da natureza viva e dos limites dos diferentes sistemas explicativos, a contraposição entre os mesmos e a percepção de que a ciência não tem respostas definitivas para tudo, sendo uma de suas características a possibilidade de ser questionada e de se transformar. Deve permitir, ainda, a compreensão de que os modelos na ciência servem para explicar tanto aquilo que podemos observar diretamente como também aquilo que só podemos inferir, e que tais modelos são produtos da mente humana e não da própria natureza, construções mentais que procuram sempre manter a realidade observada como critério de legitimação.

Segundo Carneiro e Gastal (2005), esses elementos tornam possível aos alunos entender que há uma ampla rede de relações com os diversos campos: científico, social, econômico e político.
O conhecimento da Biologia deve auxiliar o julgamento de questões polêmicas, no tocante ao aproveitamento de recursos naturais, ao desenvolvimento e à utilização de tecnologias que implicam intensa intervenção humana no ambiente, cuja avaliação deve levar em conta a dinâmica dos organismos, dos ecossistemas enfim, o modo como a natureza se comporta e a vida se processa.

Os assuntos atuais, como o desenvolvimento da Genética e da Biologia Molecular, as tecnologias de manipulação do Ácido Desoxirribonucleico (DNA) e de clonagem, trazem à tona aspectos éticos envolvidos na produção e aplicação do conhecimento científico e tecnológico, chamando à reflexão sobre as relações entre a ciência, a tecnologia e a sociedade. Conhecer a estrutura molecular da vida, os mecanismos de perpetuação, diferenciação das espécies e diversificação intraespecífica, além da importância da biodiversidade para a vida no planeta, é essencial para um posicionamento criterioso relativo ao conjunto das construções e intervenções humanas no mundo contemporâneo (FABRÍCIO et al., 2006).

Neste século, vivencia-se grande processo de criação científica, inigualável a tempos anteriores. A relação entre Ciência e Tecnologia se amplia, tornandose mais presente no cotidiano e modificando cada vez mais o mundo e o próprio ser humano. Diversas questões relativas à valorização da vida, à ética nas relações entre seres humanos, o seu meio e o planeta, ao desenvolvimento tecnológico e sua direta relação com a qualidade de vida marcam fortemente este século, colocando em discussão os valores envolvidos na produção e aplicação do conhecimento científico e tecnológico.

No ensino de Biologia, enfim, é fundamental para o desenvolvimento de posturas e valores relacionados às interações entre os seres humanos, entre eles e o meio, entre o ser humano e o conhecimento, contribuindo para uma educação que formará cidadãos solidários e sensíveis, conscientes dos processos e regularidades de mundo e da vida, capazes assim de realizar ações práticas, de fazer julgamentos e de tomar decisões (SÃO PAULO, 2008b). 


\section{Recursos didáticos no ensino de Ciências e Biologia}

A LDB (Lei n. ${ }^{\circ}$ 9.394, de 20 de dezembro de 1996) propõe um projeto pedagógico que vá além de lousa, giz e palestra do professor, a fim de preparar melhor $\mathrm{o}$ educando para os desafios de mercado de trabalho. Nesse sentido, o professor, como principal mediador da aprendizageme da relação com os alunos, necessita de apoio e/ou suporte para desenvolver seu trabalho e estar preparado para fornecer os conhecimentos necessários exigidos dentro de um conteúdo acadêmico pré-estabelecido (ESCOLANO, 2004).

Cada docente deve encontrar uma forma mais adequada de integrar as várias tecnologias e procedimentos metodológicos. Mas também é importante que amplie, que aprenda a dominar as formas de comunicação interpessoal e as de comunicação audiovisual.

Este artigo não tem a pretensão de apresentar receitas, porque as situações são muito diversificadas e há vários fatores que influenciamo processo de ensino e aprendizagem no ambiente escolar. É importante que cada docente encontre o que o faça sentir-se bem, comunicar-se bem, ensinar bem, auxiliando os alunos nesse processo de aprendizagem; em contrapartida, é importante diversificar as formas de ministrar aula, de realizar atividades, de avaliar.

As experiências (OLIVEIRA e FISCHER, 2007; LINSINGEN, 2007; POSSOBOM et al., 2003; entre outras) mostram que há inúmeras possibilidades de diversificação das metodologias de ensino com resultados muito interessantes, facilitando assim o processo de ensino e aprendizagem.

É importante destacar que ao professor deverá ser dada a possibilidade de produzir um material próprio, inovador e que vá além do livro. Nesse caso, é necessário ampliar as possibilidades no ensino e inserir novos recursos didáticos em sala de aula, o que deve ser considerado e aceito de forma aberta pelo professor. É preciso abandonar preconceitos, pensar na viabilidade e, principalmente, na necessidade de enriquecer ferramentas de trabalho, que proporcionarão melhoria no ensino e precisam ser urgentemente avaliadas pelos educadores de hoje.

\section{A experimentação como forma de ensinar}

Na maioria das vezes, o professor depara-se na sala de aula com perguntas a respeito de questões atuais de Ciências e Biologia, envolvendo temas como transgênicos, células-troncos, biotecnologia, entre outros.

Essas questões científicas e tecnológicas passaram a ter grande influência na vida de toda a sociedade, convivendo com as maravilhas das novas tecnologias, mas também com as consequências do impacto da atividade humana sobre os ambientes.

Diante disso, muitos professores, preocupados com a banalização do ensino, acreditam que a Ciência e a Biologia devam ter outras funções além daquelas tradicionalmente propostas no currículo escolar. Segundo essa tendência, os jovens deverão ser preparados a enfrentar e resolver problemas com nítidos componentes biológicos e científicos. De acordo com Krasilchik (2005), os objetivos do ensino dessas disciplinas seriam: aprender conceitos básicos, analisar o processo de pesquisa científica e analisar as implicações sociais da Ciência e da Tecnologia.

A Ciência e a Biologia podem ser as disciplinas mais relevantes e merecedoras da atenção dos educandos ou as mais insignificantes e pouco atraentes, dependendo do que for ensinado e dos recursos disponíveis para esse processo.

Fernandes (1998) destaca que a maioria dos alunos vê a Ciência e a Biologia como disciplinas cheias de nomes, ciclos e tabelas a serem decorados. Assim, a questão que se coloca é: como atrair os alunos ao estudo e como estimular seu interesse e participação?

Para responder a essa questão não pode haver uma fórmula única, pois, como já apontamos, cada situação de ensino é diferente da outra. É preciso buscar soluções, refletir sobre o tema e trocar experiências.

Além disso, consideramos fundamental a busca por novos recursos didáticos, que levem os alunos a confrontar-se com experimentos de caráter investigativo para que, diante de um fenômeno em estudo, imprimam suas próprias concepções e conclusões. É fundamental que o aluno seja instigado 
a propor uma explicação e a confronte com o conhecimento científico aprendido, gerando um conflito cognitivo, um dos motores da evolução conceitual.

Segundo Krasilchik (2005, p.86), "as aulas de laboratório têm um lugar insubstituível no ensino da Ciência e Biologia, pois desempenham funções únicas: permitem que os alunos tenham contato direto com os fenômenos, manipulando os materiais e equipamentos e observando organismos".

As aulas práticas ou experimentais são um recurso pedagógico de grande importância, em que os educandos põem em prática hipóteses e ideias aprendidas em sala de aula sobre fenômenos naturais ou tecnológicos e que estão presentes em seu cotidiano (MORAES, 1998). Por mais simples que seja a experiência, ela se torna rica ao revelar as contradições entre o pensamento do aluno, o limite de validade das hipóteses levantadas e o conhecimento científico.

Com as aulas práticas ou experimentais, espera-se que o educando construa um conhecimento significativo e não simples memorização, sem valor algum. Segundo as propostas "construtivistas", uma aprendizagem significativa requer a participação dos atores envolvidos na construção do conhecimento (MORAES, 1998).

Todavia, a implantação dessa modalidade didática, segundo Moreira e Diniz (2003), parece ser desfavorável na visão de alguns docentes, o que resulta na inoperância dos laboratórios das escolas. Além disso, questiona-se também se as atividades denominadas "experimentais" têm assumido realmente esse caráter ou são aulas meramente demonstrativas.

Entretanto, dados disponíveis em estudos na área (KRASILCHIK, 2005; POSSOBOM et al., 2003) apontam que é inegável que a experimentação tem sido um dos grandes problemas do ensino atual, quer pela ausência de laboratórios em muitas escolas, quer pela inexperiência dos professores, ou ainda pelos currículos sobrecarregados. Contudo, alguns trabalhos nessa área mostram resultados satisfatórios. Possobom et al. (2003) citam que, em uma escola estadual localizada no município de Botucatu-SP, observou-se que, apesar das precárias condições apresentadas com relação a materiais e espaço para atividades de laboratório, foi possível superar os problemas, ou a maior parte deles, adaptando os diversos ambientes disponíveis e utilizando materiais simples e de baixo custo, proporcionando um aprendizado mais eficiente e mais motivador que as tradicionais aulas expositivas.

\section{O livro de Ciência e Biologia como recurso didático}

Os livros de Ciências e Biologia, diferentemente dos demais livros, têm a função da aplicação do método científico, estimulando a análise de fenômenos, o teste de hipóteses e a formulação de conclusões. Adicionalmente, devem proporcionar ao aluno uma compreensão filosófica, científica e estética de sua realidade, oferecendo suporte no processo de formação dos cidadãos (VALENTE, 1993).

Segundo Bizzo (2002), historicamente, os livros didáticos têm sido compreendidos como agentes determinantes de currículos, limitando a inserção de novas abordagens e possibilidades de contextualização do conhecimento.

Diante dessas impropriedades, tornou-se evidente a necessidade de criar instrumentos para adequar os livros didáticos a uma nova realidade educacional, comprometida com as demandas sociais. Tanto a comunidade científica como as escolas (públicas e particulares) e o próprio governo federalemitiram sinais de preocupação nesse sentido (VASCONCELOS; SOUTO, 2003).

Entretanto, os livros didáticos podem apresentarse como um importante apoio pedagógico, visto que não contêm apenas linguagem textual, mas sim outros elementos informativos que facilitam a atividade docente, a compreensão pelo aluno, e subsidiam a aprendizagem.

Os recursos visuais fornecem suporte vital às ideias e informações contidas no livro, e por isso merecem atenção especial. A observação das imagens veiculadas pelos livros didáticos contempla questões como a qualidade da impressão, a sua inserção ao longo do texto e a relação estabelecida entre texto e imagem. Nos livros didáticos predominam imagens altamente didatizadas. Além do mais, Bruzzo (2004) afirma que 
o conhecimento das Ciências Naturais está intrinsecamente associado à apreciação de imagens e ilustrações, pois isso facilita a interação dos alunos com os conteúdos e com as vivências do seu cotidiano

A função das ilustrações é tornar as informações mais claras, estimulando a compreensão e a interação entre leitores e o texto científico.

Além disso, muitos livros contêm recursos complementares ou adicionais, como glossários, atlas ilustrativos, cadernos de atividades, guias experimentais, e oferecem novas oportunidades de exercitar o conhecimento em construção e proporcionam melhor compreensão das informações trabalhadas ao longo da obra.

\section{Novas Tecnologias de Informação e Comunicação - TIC's no ensino de Ciências e Biologia}

As autoridades políticas, professores e pesquisadores têm considerado o uso de novas Tecnologias de Informação e Comunicação - TIC's na educação, um movimento necessário na formação dos alunos, já que a tendência do mercado de trabalho é a máxima exigência do indivíduo quanto às suas qualificações científicas e tecnológicas.

Por isso, o conhecimento não pode ficar restrito ao simples aprendizado adquirido nas tradicionais salas de aula, pois só o exame crítico do conhecimento leva à descoberta. É preciso buscar novas dimensões para o uso de tecnologias, através de uma visão democrática e coerente da realidade brasileira.

Segundo Oliveira e Fischer (2007), a informática se apresenta como um importante aliado da educação, uma ferramenta de trabalho no apoio pedagógico que, por seu caráter interativo, motiva e auxilia positivamente os alunos na construção do conhecimento, desde que o professor crie situações de aprendizagem adaptadas à sua realidade.

Apesar dos fortes apelos da mídia e das qualidades inerentes ao computador, a sua dispersão nas escolas está hoje abaixo do que se anunciava e se desejava. A informática na educação ainda não penetrou as ideias dos educadores e, por isso, não está firmada no sistema educacional.

O proveito do computador em relação ao âmbito educacional está relacionado à sua característica de interatividade, à sua grande probabilidade de ser um instrumento que pode ser utilizado para promover a aprendizagem individualizada, visto que ele só executa o que se ordena; assim sendo, limita-se aos potenciais e anseios humanos.

Entretanto, outra questão importante destacada por Valente (1993, p.7) diz respeito à formação do professor para o uso dessas novas tecnologias, que não pode ficar restrita ao domínio da máquina, mas deve ser vista num contexto mais amplo das possibilidades que a envolvem. Ou seja, a formação "deve oferecer condições para o professor construir conhecimento sobre técnicas computacionais e entender por que e como integrar o computador em sua prática pedagógica".

Segundo Moran (2000), o papel do professor é fundamental nos projetos de inovações, até porque a qualidade de um ambiente tecnológico de ensino depende muito mais de como ele é explorado didaticamente do que de suas características técnicas. A simples presença de novas tecnologias na escola não é, por si só, garantia de maior qualidade na educação, pois a modernidade pode mascarar um ensino tradicional, baseado na recepção e na memorização de informações.

\section{O uso de histórias em quadrinhos no ensino de Ciências e Biologia}

A utilização de histórias em quadrinhos como recurso didático, segundo especialistas (KAMEL, 2006; MOYA, 1977), é extremamente relevante para o ensino de Ciência e Biologia, nos mais diversos níveis de ensino. Inúmeros trabalhos encontrados, no Brasil e no exterior, confirmam o uso desse recurso para a efetivação do ensino dessas disciplinas.

Segundo Moya (1977), os quadrinhos são uma forma de comunicação rápida e internacional, em relação a todas as formas modernas de contato entre os homens deste século. Na visão de Cirne (2000), os quadrinhos são uma literatura marcada por ideias, com 
o objetivo atingir um determinado objetivo. Seus textos se apresentam como unidades comunicativas, manifestam intenções diferentes: informar, convencer, seduzir, divertir, sugerir estados de ânimo, entre outras .

Como recurso didático pedagógico, o interesse do uso das histórias em quadrinhos em sala de aula parte da intenção de propor uma nova perspectiva metodológica para o ensino, especialmente de Ciências e Biologia.

Inúmeros estudiosos e pesquisadores que discutem o assunto (GONÇALVES e MACHADO, 2005; CIRNE, 2000) acreditam, quase de forma unânime, na utilização das histórias em quadrinhos como meio pedagógico, com o objetivo de ativar o desenvolvimento do educando pela leitura, despertando sua criatividade, descobrindo seu lado artístico e crítico. Além do mais, usar os quadrinhos como método de ensino proporciona um melhor entendimento sobre determinados conceitos, ajudando o aluno a compreender melhor algumas abstrações.

$\mathrm{O}$ assunto é amplamente discutido no meio acadêmico nacional e internacional, através de dissertações e artigos, que apresentam propostas de análise e utilização de quadrinhos não apenas como recurso para a educação científica, mas também como meio para divulgação das Ciências.

A autora Linsingen (2007), em seu artigo "Mangás e sua utilização pedagógica no ensino de Ciências sob a perspectiva CTS", aponta características presentes nos quadrinhos que permitem o debate de seus conteúdos sob o enfoque Ciência, Tecnologia e Sociedade, e destaca a busca de alternativas que atraiam o interesse do estudante ou mesmo que diminuam essa distância conceitual entre este e o professor.

Outros importantes trabalhos, que contribuem para as reflexões acerca do uso de quadrinhos em aulas de Ciências e Biologia, são debatidos pelos autores Gonçalves e Machado (2005), que propõem a utilização de quadrinhos como recurso didático nas séries iniciais, para a discussão dos conteúdos ministrados. Em um de seus trabalhos, os autores analisam 261 revistas da "Turma da Mônica", de
Maurício de Sousa, e concluem que, apesar dos diversos erros conceituais nas histórias, essa constatação não impede o alcance desse material como instrumento didático para fomentar discussões em aulas de Ciências e Biologia. Assim, destacam o papel fundamental do professor como mediador das discussões entre a mensagem do material e o conteúdo curricular nas referidas disciplinas.

Por fim, Testoni (2004) aponta como reflexão a importância do papel do professor na compreensão crítica do enredo dessas histórias, na seleção desse material e no planejamento das atividades nas quais pretende utilizar as histórias em quadrinhos como instrumento de reflexão para as aulas de Ciências e Biologia.

A história em quadrinhos é apenas mais um dos instrumentos a serviço de práticas motivadoras e inovadoras no ensino de Ciências, que devem ser planejadas com o intuito de promover aos educandos um olhar mais crítico e sistemático acerca das informações recebidas não apenas pelos quadrinhos, mas por qualquer outro meio de divulgação científica, ou não, que seja passível de análise e equívoco.

\section{Considerações finais}

O ensino de Ciências e Biologia ainda se encontra distante do proposto nos documentos oficiais que regem a educação; entretanto, tem-se percebido uma mudança nas estratégias didáticas utilizadas na abordagem dos conteúdos, para que a aprendizagem ocorra de forma mais significativa.

Os recursos didáticos são instrumentos complementares que ajudam a transformar as ideias em fatos e em realidades, contribuindo para uma melhoria no referido processo. Por meio desses mecanismos, os professores têm a oportunidade de tornar as aulas mais dinâmicas e interessantes, além de auxiliar na transferência de situações, experiências, demonstrações, sons, imagens e fatos para o campo da consciência, onde então eles se transformam em ideias claras e inteligíveis; entretanto, eles em si não fazem milagre se o professor não estiver capacitado e comprometido com seu trabalho. 
O uso de recursos didáticos como estratégia no ensino...

Por fim, pode-se considerar que, em um contexto didático, a função dos recursos didáticos é sedimentar os conteúdos escolares, ou seja, mediar as relações de forma que os alunos se apropriem dos conteúdos escolares. Aliás, esse deve ser o objetivo maior de sua utilização no processo ensino e aprendizagem. $\mathrm{O}$ grande desafio do educador é tornar o ensino de Ciências e Biologia prazeroso e instigante, sendo capaz de desenvolver no aluno o saber científico e o gosto por essas disciplinas.

\section{REFERÊNCIAS}

AZEVEDO, F. et al. Manifestos dos pioneiros da Educação Nova (1932) e dos educadores 1959. Recife: Fundação Joaquim Nabuco, Editora Massangana, 2010.

BIZZO, N. Ciência fácil ou difícil? 2.ed, São Paulo: Ática, 2002.

BRASIL. Secretaria de Educação Fundamental. Parâmetros Curriculares Nacionais: Ciências Naturais. Secretaria de Educação Fundamental. Brasília: MEC/SEF, 1998.

BRASIL. Secretaria de Educação Fundamental. Parâmetros Curriculares Nacionais: Ensino Médio. Brasíli: MEC/SEF, 2000.

BRUZZO, C. Biologia: educação e imagem. Educação e Sociedade, Campinas, v.25, n.89, p. 1359-1378, set./dez. 2004.

CARNEIRO, M. H. S.; GASTAL, M. L. História e filosofia das ciências no ensino de biologia. Ciência \& Educação, São Paulo, v. 11, n. 1, p. 33-39, 2005.

CECCON, S. Trilhas interpretativas como estratégia metodológica para o ensino médio de biologia. 2008. Disponível em: http://www.pucpr.br/ eventos/educere/educere2008/anais/pdf/ 553_322.pdf. Acesso em: 18 ab. 2011.
CIRNE, M., Quadrinhos, sedução e paixão. Petrópolis: Vozes, 2000.

ESCOLANO, A. C. M. Fatores de risco e de proteção na trajetória de desenvolvimento de escolares de $1 .^{a}$ a $4 .^{a}$ série do ensino

fundamental. 2004, 258f. Tese (Doutorado em Psicologia) - Faculdade de Filosofia, Ciências e Letras de Ribeirão Preto, USP. Ribeirão Preto, 2004.

FABRÍCIO, M. F. L. et al., A compreensão das Leis de Mendel por alunos de biologia na educação básica e na licenciatura. Ensaio - pesquisa em educação em ciência, São Paulo, v.8, n.1, p. 1-21, jul. 2006.

FERNANDES, H. L. Um naturalista na sala de aula. Ciência \& Ensino, Campinas, v. 5, p. 3-5, dez. 1998.

GONÇALVES, R.; MACHADO, D. M. Comics: investigación de conceptos y de términos paleontológicos, y uso como recurso didáctico em la educación primaria. Enseñanza de las Ciências, Barcelona, v. 23, n.2, p. 263-274, 2005.

KAMEL, C. R. L. Ciências e quadrinhos: explorando as potencialidades das histórias como materiais instrucionais. 2006. 113f. Dissertação (Mestrado em Ensino em Biociências e Saúde) Instituto Oswaldo Cruz - Fiocruz, Rio de Janeiro, 2006.

KRASILCHIK, M. Prática de ensino de biologia. 4.ed. São Paulo: Universidade de São Paulo, 2005.

LINSINGEN, L. V. Mangás e sua utilização pedagógica no ensino de ciências sob a perspectiva. CTS. Ciência \& Ensino, São Paulo, v. 1, n. especial, Nov.2007.

MOREIRA, M. L.; DINIZ, R. E. S. O laboratório 
de Biologia no Ensino Médio: infraestrutura e outros aspectos relevantes. In: Universidade Estadual Paulista - Pró-Reitoria de Graduação. (Org.). Núcleos de Ensino. São Paulo: Editora da UNESP, v. 1, p. 295-305, 2003.

MORAES, R. O significado da experimentação numa abordagem construtivista: $O$ caso do ensino de ciências. In: BORGES, R. M. R.; MORAES, R. (Org.) Educação em ciências nas séries iniciais. Porto Alegre: Sagra Luzzato, 1998.

MORAN, J. M. As novas tecnologias e mediação pedagógica. São Paulo: Papirus, 2000.

MOYA, A. Era uma vez um menino amarelo.

São Paulo: Perspectiva, 1977.

OLIVEIRA, E. C. P.; FISCHER, J. Tecnologia na aprendizagem - a informática como alternativa no processo de ensino. Revista de Divulgação Técnico-científica do ICPG, v. 3, n. 10, jan./jun. 2007.

PADUA, E. M. M. Metodologia de pesquisa: abordagem teórico-prática. 6.ed. Campinas: Papirus, 2000.

POSSOBOM, C. C. F. et al. As atividades práticas de laboratório no ensino de Biologia e Ciências: relato de uma experiência.

In: . Universidade Estadual Paulista -

Pró-Reitoria de Graduação. (Org.). Núcleos de Ensino. São Paulo: Editora da UNESP, v. 1, p. 113-123, 2003.

\section{SÃO PAULO. Proposta Curricular do Estado de}

São Paulo: Ciências. São Paulo: SEE, 2008a.

SÃO PAULO. Proposta Curricular do Estado de São Paulo: Biologia. São Paulo: SEE, 2008b.

TESTONI, L. A. Um corpo que cai: as histórias em quadrinhos no ensino de física, 2004. 158f. Dissertação (Mestrado em Educação). Faculdade de Educação da Universidade de São Paulo, São Paulo, 2004.

VALENTE, J.A. Diferentes usos do computador na educação. In: Computadores e conhecimento: repensando a educação. Campinas: UNICAMP, 1993. p. 1-23.

VASCONCELOS, S. D.; SOUTO, E. O livro didático de ciências no ensino fundamental proposta de critérios para análise do conteúdo zoológico. Ciência \& Educação, v. 9, n. 1, p. 93104, 2003.

RECEBIDO EM 20/2/2013

ACEITO EM 17/4/2013 